THE JOURNAL OF CHEMICAL PHYSICS - VOLUME 16, NUMBER 2 FEBRUARY, 1948

\title{
The Molecular Structure of Dimethyltrisulfide, $\left(\mathrm{CH}_{3}\right)_{2} \mathrm{~S}_{3}{ }^{*}$
}

\author{
Jerry Donohue and Verner Schomaker \\ Department of Chemistry, ${ }^{* *}$ California Institute of Technology, Pasadena, California
}

(Received July 1, 1947)

\begin{abstract}
Dimethyltrisulfide $\left(\mathrm{CH}_{3}\right)_{2} \mathrm{~S}_{3}$ has been investigated by the electron diffraction method. The molecule was found to have the chain configuration, with the following interatomic distances and angles: $\mathrm{C}-\mathrm{H}=1.09 \mathrm{~A}$ (assumed), $\mathrm{C}-\mathrm{S}=1.78 \pm 0.04 \mathrm{~A}, \mathrm{~S}-\mathrm{S}=2.04 \mathrm{~A}, \pm 0.02 \mathrm{~A}, \angle \mathrm{H}-\mathrm{C}-\mathrm{S}$ $=112^{\circ}$ (assumed), $\angle \mathrm{S}-\mathrm{S}-\mathrm{S}=104^{\circ} \pm 5^{\circ}$, and $\angle \mathrm{C}-\mathrm{S}-\mathrm{S}=104^{\circ} \pm 5^{\circ}$. The results also suggest that the $\mathrm{C}-\mathrm{S}$ bonds oscillate with rather large amplitude about a mean position approximately $106^{\circ}$ out of the plane of the three sulfur atoms.
\end{abstract}

$T$ $\mathrm{HE}$ present electron diffraction investigation was undertaken mainly to determine whether dimethyltrisulfide is a simple trisulfide (I), a thiodisulfide (II), or a dithiosulfone (III).<smiles>CSSSC</smiles><smiles>CS[SH](C)S</smiles>

II<smiles>CS(C)(S)S</smiles>

III
Knowledge of this structure is of interest in connection with the problems of the constitutions of the inorganic persulfides and polythionates, ${ }^{1}$ as well as of the alkyl polysulfides, ${ }^{2}$ and the Thiokols. ${ }^{3}$ With the exception of the trithionate ion, ${ }^{4} \mathrm{O}_{3} \mathrm{~S}-\mathrm{S}-\mathrm{SO}_{3}=$, there is no direct structural evidence which settles the question whether the molecules of these substances have the chain configuration or are related to II or III. In the case of the disulfides $\mathrm{H}_{2} \mathrm{~S}_{2}, \mathrm{~S}_{2} \mathrm{Cl}_{2}$, and $\left(\mathrm{CH}_{3}\right)_{2} \mathrm{~S}_{2}$, the existing evidence from electron

\footnotetext{
* The work herein was done under Contract OEMsr-753 between the National Defense Research Committee and the California Institute of Technology.

** Contribution No. 1108 from the Gates and Crellin Laboratories of Chemistry, California Institute of Technology.

1 D. M. Yost and H. Russell, Systematic Inorganic Chemistry (Prentice Hall, Inc., New York, 1944), p. $361 \mathrm{ff}$.

$2 \mathrm{R}$. Connor, Organic Chemistry (John Wiley and Sons, Inc., New York, 1943), edited by H. Gilman, p. 864.

3 S. M. Martin and J. C. Patrick, Ind. Eng. Chem. 28, 1144 (1936).

4 W. H. Zachariasen, Phys. Rev. 37, 1295 (1931).
}

diffraction favors chain structures for all three molecules. $^{5-7}$

\section{EXPERIMENTAL}

The sample used in this investigation was provided by Professor R. C. Fuson. It was pale yellow in color and was used without further purification. Excellent electron diffraction photographs were made in the apparatus described by Brockway ${ }^{8}$ with the use of the high temperature nozzle. ${ }^{9}$ At the end of each run the boiler and remaining liquid were examined; no corrosion of the boiler and only slight darkening of the liquid were observed, indicating that very little decomposition occurred.

\section{INTERPRETATION OF THE PHOTOGRAPHS}

The characteristic features of the photographs are represented by.curve $\mathrm{V}$ of Fig. 1, which was drawn in accordance with the measured ring diameters (except that the unobservable first maximum, which is not structure sensitive, was added arbitrarily), so as to have the general properties of theoretical intensity curves calculated with the simplified expression

$$
I(q)=\sum_{i, j} \frac{Z_{i} Z_{j}}{r_{i j}} \exp \left(-b_{i j} q^{2}\right) \sin \left(\frac{\pi}{10} r_{i j q}\right) .
$$

${ }^{5}$ K. J. Palmer, J. Am. Chem. Soc. 60, 2360 (1938).

${ }^{6}$ D. P. Stevenson and J. Y. Beach, J. Am. Chem. Soc. 60, 2872 (1938).

${ }^{7}$ P. G. Ackerman and J. E. Mayer, J. Chem. Phys. 4, 377 (1936).

${ }_{8}$ L. O. Brockway, Rev. Mod. Phys. 6, 234 (1936). Camera distance, $10.91 \mathrm{~cm}$. Electron wave-length, $0.0610 \mathrm{~A}$ calibrated with respect to zinc oxide smoke (C.S. Lu and E. W. Malmberg, Rev. Sci. Inst. 14, 271 (1943)) and corrected for film expansion.

${ }^{9}$ L. O. Brockway and K. J. Palmer, J. Am. Chem. Soc. 59, 2181 (1937). 
The radial distribution integral, ${ }^{10}$ curve $R D$ of Fig. 1, was calculated by use of the formula

$$
r D(r)=\sum_{q=1,2, \ldots}^{100} I(q) \exp \left(-a q^{2}\right) \sin [(\pi / 10) q r],
$$

with $\exp \left(-a(100)^{2}\right)=0.1$. The integral has maxima at $1.78 \mathrm{~A}, 2.04 \mathrm{~A}, 2.45 \mathrm{~A}, 3.02 \mathrm{~A}$ (very broad, asymmetric peak), and $4.0 \mathrm{~A}$ (very broad, small peak). Of these peaks the first two may be interpreted as representing, respectively, the bonded $\mathrm{C}-\mathrm{S}$ and $\mathrm{S}-\mathrm{S}$ distances, the third the non-bonded S...H distance, and the asymmetric fourth the non-bonded C...S and S...S interrelations. The interpretation of the weak maximum at $4.0 \mathrm{~A}$ is discussed below.

An extensive investigation of the straight chain structure I by the correlation procedure was made. For structure I four parameters are required to define the structure if the positions of the hydrogen atoms are assumed and if the long, rotation-dependent, C...S distance is neglected. These may be chosen as: (1) bonded $\mathrm{C}-\mathrm{S}$; (2) bonded S-S ; (3) non-bonded S. . S ; and (4) non-bonded C...S.

The first two of these parameters may be determined directly from the radial distribution integral. As a check on the accuracy of this determination, twenty-one intensity curves, some of which are shown in Fig. 1, were calculated for models with varying ratios between these two distances. In these models the $\mathrm{S}-\mathrm{S}$ distance was held at $2.04 \mathrm{~A}$ and the non-bonded C...S and $\mathrm{S}$...S distances were varied in a systematic fashion so that their average was in general agreement with the broad maximum of the integral at 3.0-3.2A. Best agreement between the calculated curves and the appearance of the photographs was obtained for models with $\mathrm{C}-\mathrm{S}$ $=1.78 \mathrm{~A}$ as was expected, changes of more than $0.03 \mathrm{~A}$ giving marked discrepancies regardless of the particular values used for the non-bonded C...S and S...S distances.

The determination of the two remaining parameters is a more difficult problem since the terms which are involved in their variation contribute only about 20 percent of the total scattering. Since the term representing the two

\footnotetext{
${ }^{10}$ a. R. Spurr and V. Schomaker, J. Am. Chem. Soc. 64, $2693(1942)$; b. P. A. Shaffer, Jr., V. Schomaker, and L. Pauling, J. Chem. Phys 14, 659 (1946).
}

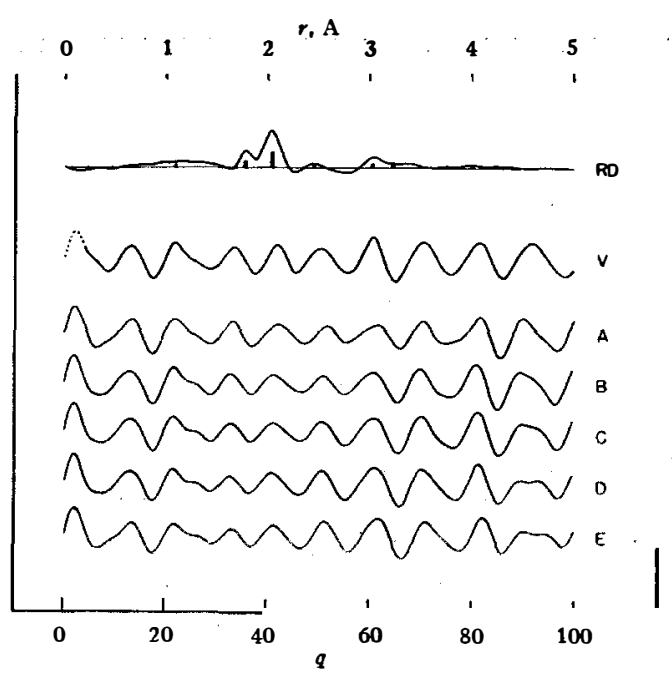

FIG. 1. Electron diffraction curves for dimethyltrisulfide. Chain models with $\mathrm{C}-\mathrm{H}=1.09 \mathrm{~A}, \mathrm{~S}-\mathrm{S}=2.04 \mathrm{~A}, \mathrm{~S} \ldots \mathrm{H}$ $=2.45 \mathrm{~A}, \mathrm{C} \ldots \mathrm{S}=3.02 \mathrm{~A}, \mathrm{~S} . \mathrm{S}=3.22 \mathrm{~A}\left(\angle \mathrm{S}-\mathrm{S}-\mathrm{S}=104^{\circ}\right)$, and $b_{C} \ldots \mathrm{H}=0.00016$; the other molecular parameters are as follows.

$\begin{array}{cccc}\text { Model } & \mathrm{C}-\mathrm{S} & b_{\mathrm{S}} \ldots \mathrm{H} & (\angle \mathrm{C}-\mathrm{S}-\mathrm{S}) \\ \cdot A & 1.83 & 0 & 102^{\circ} 45^{\prime} \\ B & 1.81 & 0.0003 & 103^{\circ} 30^{\prime} \\ C & 1.78 & 0.0003 & 104^{\circ} \\ D & 1.75 & 0.0003 & 105^{\circ} \\ E & 1.73 & 0 & 106^{\circ} 30^{\prime}\end{array}$

All other $b_{i j}=0$. The long C...S term at $4.00 \mathrm{~A}$, was included with $b=0.0009$, for models $B, C$, and $D$, and was omitted for the other models.

non-bonded C...S distances and the term for the non-bonded S...S distance are of nearly equal weight, it is impossible to distinguish between them. For example, a curve calculated for a model with $\angle \mathrm{S}-\mathrm{S}-\mathrm{S}=\angle \mathrm{S}-\mathrm{S}-\mathrm{C}=104^{\circ}$ is indistinguishable from one calculated for a model with $\angle \mathrm{S}-\mathrm{S}-\mathrm{S}=95 \frac{1}{2}^{\circ}$ and $\angle \mathrm{S}-\mathrm{S}-\mathrm{C}$ $=115^{\circ}$. However, it is appropriate to choose $\mathrm{S}$...S $<\mathrm{C} \ldots \mathrm{S}$ so that the sulfur bond angles $\angle \mathrm{S}-\mathrm{S}-\mathrm{S}$ and $\angle \mathrm{S}-\mathrm{S}-\mathrm{C}$ have similar values, and this is done in the following analysis.

Twenty-two scattering curves, some of which are shown in Fig. 2, were calculated for models with varying values of these distances. It was found that it is not possible to obtain theoretical scattering curves in agreement with the appearance of the photographs unless (1) a distance at 4.0A as suggested by the radial distribution integral is included in the intensity formula and (2) the S...S distance is given a rather severe temperature factor. The distance at $4.0 \mathrm{~A}$ corresponds to the two longer non-bonded C...S distances in a non-planar model with the $\mathrm{C}-\mathrm{S}$ 
bonds rotated by $106^{\circ}$ out of the plane containing the three sulfur atoms. This is just the angle of twist between the $\mathrm{O}-\mathrm{H}$ bonds in hydrogen peroxide, as deduced from the crystal structure of $\mathrm{H}_{2} \mathrm{O}_{2}$. urea. ${ }^{11}$ Unless this distance is included in the calculation, the character of the first maximum and adjacent minima is in definite disagreement with the appearance of the photographs and curve $\mathrm{V}$, the theoretical curves having their sharp first minima just at the observed position of the weak first maximum, and a weak shoulder (which might be interpreted as corresponding to the observed first minimum) at the observed position of the second minimum. This discrepancy cannot be regarded as merely a difficulty in interpretation, in view of our knowledge of the appearance of electron diffraction photographs and their interpretation, but must be regarded as conclusive. On the curve for the accepted model, $\mathrm{O}$, on the other hand, the positions of the

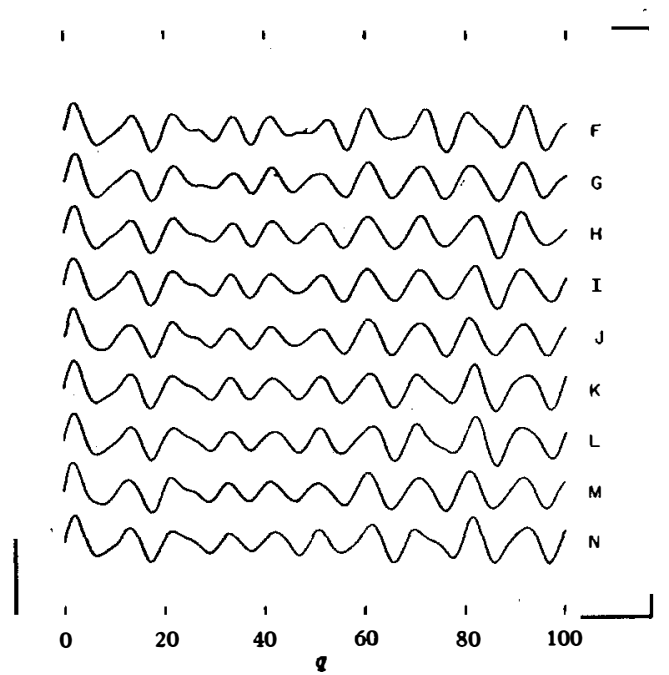

FIG. 2. Electron diffraction curves for dimethyltrisulfide. Chain models with $\mathrm{C}-\mathrm{H}=1.09 \mathrm{~A}, \mathrm{C}-\mathrm{S}=1.78 \mathrm{~A}, \mathrm{~S}-\mathrm{S}$ $=2.04 \mathrm{~A}, \mathrm{~S} . . \mathrm{H}=2.45 \mathrm{~A}$, and $b_{\mathrm{C}} \ldots \mathrm{H}=0.00016$; all other $b_{i j}=0$ except for models $J$ and $M$, for which $b_{\mathrm{s}} . . \mathrm{s}=0.0003$; the other parameters are as follows.

\begin{tabular}{|c|c|c|c|c|}
\hline $\begin{array}{c}\text { Model } \\
F \\
G \\
H \\
I \\
J \\
K \\
M \\
N\end{array}$ & $\begin{array}{l}\text { C...S } \\
3.10 \\
2.96 \\
2.97 \\
3.02 \\
3.05 \\
3.02 \\
3.05 \\
3.00\end{array}$ & $\begin{array}{l}\text { S...S } \\
3.10 \\
3.10 \\
3.14 \\
3.17 \\
3.20 \\
3.22 \\
3.25 \\
3.25\end{array}$ & $\begin{array}{c}(\angle \mathrm{S}-\mathrm{S}-\mathrm{S}) \\
99^{\circ} \\
99^{\circ} \\
100^{\circ} 30^{\prime} \\
102^{\circ} \\
103^{\circ} \\
104^{\circ} \\
105^{\circ} 30^{\prime} \\
105^{\circ} 30^{\prime}\end{array}$ & $\begin{array}{c}(\angle \mathrm{C}-\mathrm{S}-\mathrm{S}) \\
108^{\circ} 20^{\prime} \\
101^{\circ} 30^{\prime} \\
101^{\circ} \\
104^{\circ} \\
105^{\circ} 40^{\prime} \\
102^{\circ} \\
105^{\circ} 40^{\prime} \\
103^{\circ} 20^{\prime}\end{array}$ \\
\hline
\end{tabular}

The long $\mathrm{C} \ldots \mathrm{S}$ at $4.00 \mathrm{~A}$ term was included with $b=0.0009$, for models $J$ and $M$, and was omitted for the other models.

${ }^{11}$ C. S. Lu, E. W. Hughes, and P. A. Giguère, J. Am. Chem. Soc. 63, 1507 (1941). features corresponding to the measured first and second minima and the first maximum are satisfactory. The relative depths of the indicated first and second minima, also, are in better agreement with curve $\mathrm{V}$ than on the curves calculated without a $4.0 \mathrm{~A}$ term. The agreement is not perfect either in this respect or for the magnitude of the first maximum, which on the photographs is clearly visible, although very weak, but on curve $\mathrm{O}$ is indicated only as a region of unusually small upward curvature; however, these discrepancies do seem to represent difficulties of interpretation.

Similar differences between the correct and the obvious interpretation of a weak inner ring-the ring appearing stronger on the photographs than would be suggested by the correct theoretical curve, or the apparent relative depths of the adjacent minima being different from that shown by the theoretical curve-have been previously observed in the case of numerous other compounds of which propane ${ }^{12}$ is an example. Curve $Z_{i} Z_{j}$, for which the customary coefficients $Z_{i} Z_{j} / r_{i j}$ were replaced by $Z_{i} Z_{j}$, was calculated to illustrate the notion that the apparent strength of the weak-and also relatively sharp-inner ring may be enhanced by a tendency of the eye to detect more readily the higher frequency com. ponents of the pattern.

It is evident that, in general, the appearance of the innermost rings of electron diffraction photographs cannot be so simply interpreted in terms of simplified theoretical intensity curves as can the rest of the pattern, perhaps in part because of the very rapid change of total intensity with change in scattering angle at small scattering angles, and that it is never justifiable to make important use of an inner feature-such as weak inner ring-without reference to similar features on the photographs of other substances of known structure. In addition to propane, we have here made particular reference to the photographs and curves of cyclopropane, ethylene imine, and ethylene oxide, ${ }^{13}$ which show somewhat similar inner rings to that of dimethyltrisulfide.

12 S. H. Bauer, J. Chem. Phys. 4, 406 (1936) ; L. Pauling and L. O. Brockway, J. Am. Chem. Soc. 59, 1223 (1937).

${ }_{13} \mathrm{H}$. Pfeiffer, H. A. Levy, and V. Schomaker (to. be published, J. Am. Chem. Soc.). 
Curve $\mathrm{O}$ was calculated with the following values of the temperature factor $b: \mathrm{C}-\mathrm{H}$ : $0.00016 ; \mathrm{S} . \mathrm{H}: 0.0003 ; \mathrm{S} . . \mathrm{S}: 0.0003$; long C....S:0.0009; all others zero, except for the remaining distances involving hydrogen, which were neglected. Curves $\mathrm{C}$ and $\mathrm{P}$ are identical with curve $\mathrm{O}$ except that the values zero and 0.0009 , respectively, were used for $b_{\mathrm{s} . . . s .}$. Curve $\mathrm{C}$ is unsatisfactory in regard to a number of minor details in the region $35<q<60$ of which one, regarding the relative intensity of the fourth ring, can be seen most clearly in Fig. 3. Curve $P$ is only slightly less satisfactory than curve $\mathrm{O}$. This indication of a relatively large value required for $b_{\mathrm{s} . . . . s}$ is rather surprising. We know of no other molecules in which the temperature effect is so large for a distance between heavy atoms bonded to the same atom. The large temperature factor required for the long C....S distance, on the other hand, is quite reasonable, and indicates that only a small potential restricts internal rotation at the temperature at which the photographs were made.

Scattering curves for several of the models of type II and III which were calculated are shown in Fig. 3. The only important essential differences between these models and chain structure models are differences of amplitude of the short C...S term and the long C....S term, of which the latter is most important for our argument, the essential long C...S term having only half-strength in type II models and being absent in type III models. It is seen that these curves are quite unsatisfactory with respect to the first ring. (At large scattering angles these curves and curve $\mathrm{O}$ are closely similar, none having an appreciable 4.0A contribution.) Since no variation in molecular parameters whatever makes the initial portions of these curves correspond to the appearance of the photographs, we conclude that, to the accuracy of our observations of the inner rings, neither II nor III is the structure of dimethyltrisulfide.

Our final values for the parameters of the satisfactory straight chain structure are: $\mathrm{C}-\mathrm{H}$ $=1.09 \mathrm{~A}$ (assumed), $\mathrm{C}-\mathrm{S}, 1.78 \pm 0.04 \mathrm{~A}, \mathrm{~S}-\mathrm{S}$ $=2.04 \pm 0.02 \mathrm{~A}, \quad \angle \mathrm{H}-\mathrm{C}-\mathrm{S}=112^{\circ} \quad$ (assumed), $\angle \mathrm{S}-\mathrm{S}-\mathrm{S}=104^{\circ}+5^{\circ}$, and $\angle \mathrm{C}-\mathrm{S}-\mathrm{S}=104^{\circ}$ $\pm 5^{\circ}$. (C. . S $=3.02 \pm 0.04 \mathrm{~A}$ and $\mathrm{S} . . \mathrm{S}=3.22$ $\pm 0.04 \mathrm{~A}$.) The terminal $\mathrm{CH}_{3}-\mathrm{S}$ bonds are ro-

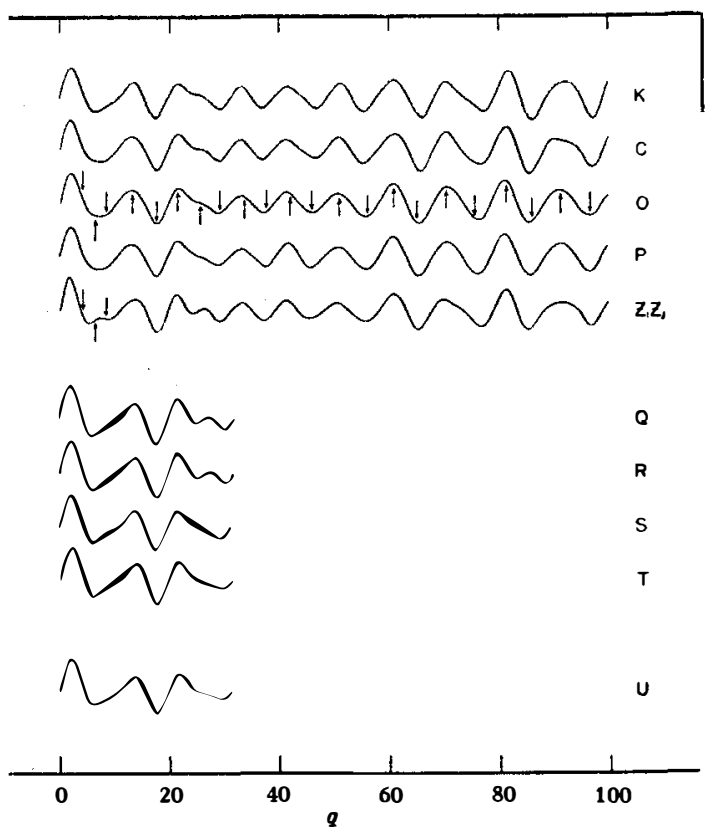

Fig. 3. Electron diffraction curves for dimethyltrisulfide. Molecular parameters for the various models are $\mathrm{C}-\mathrm{H}$ $=1.09 \mathrm{~A}, \mathrm{C}-\mathrm{S}=1.78 \mathrm{~A}, \mathrm{~S}-\mathrm{S}=2.04 \mathrm{~A}, \mathrm{~S} . . \mathrm{H}=2.45 \mathrm{~A}$, long $\mathrm{C} \ldots \mathrm{S}=4.00 \mathrm{~A}$, and $b_{\mathrm{C}} \ldots \mathrm{H}=0.00016$; the other parameters are as follows.

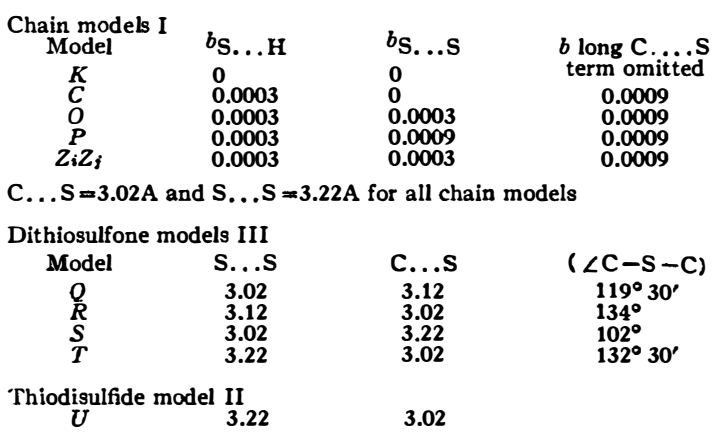

tated about $106^{\circ}$ from the plane of the sulfur chain. The quantitative comparison for model $\mathrm{O}$ is shown in Table I.

\section{DISCUSSION}

The chain structure found for dimethyltrisulfide is in agreement with the chain structures proposed for the three disulfides which have been previously investigated by the electron diffraction method, $\mathrm{H}_{2} \mathrm{~S}_{2},{ }^{6} \mathrm{~S}_{2} \mathrm{Cl}_{2},{ }^{5,7}$ and $\left(\mathrm{CH}_{3}\right)_{2} \mathrm{~S}_{2}{ }^{6}$ In all four molecules the bonded $\mathrm{S}-\mathrm{S}$ distance is $0.02-0.03 \mathrm{~A}$ shorter than the $\mathrm{S}-\mathrm{S}$ distance $2.07 \mathrm{~A}$ in $\mathrm{S}_{8 .}{ }^{14}$ The $\mathrm{C}-\mathrm{S}$ distances in $\left(\mathrm{CH}_{3}\right)_{2} \mathrm{~S}_{2}$

${ }^{14}$ C. S. Lu and J. Donohue, J. Am. Chem. Soc. 66, 818 (1944). 
TABLE I.

\begin{tabular}{|c|c|c|c|c|}
\hline Min. & Max. & $q_{\mathrm{obs}}$ & $90_{0}$ & $q_{0_{0}} / q_{\text {obs }}$ \\
\hline 1 & 1 & $\begin{array}{l}4.42 \\
6.61 \\
8.52\end{array}$ & & \\
\hline & 2 & $\begin{array}{l}13.35 \\
17.73\end{array}$ & 13.2 & 0.989 \\
\hline 3 & $\begin{array}{l}3 \\
3^{\prime}\end{array}$ & $\begin{array}{l}17.73 \\
21.59 \\
25.70\end{array}$ & $\begin{array}{l}17.7 \\
21.6\end{array}$ & $\begin{array}{r}.998 \\
1.000\end{array}$ \\
\hline 4 & & 29.37 & 29.0 & 0.988 \\
\hline 5 & 4 & $\begin{array}{r}33.85 \\
37.86\end{array}$ & $\begin{array}{l}33.0 \\
37.3\end{array}$ & $\begin{array}{l}.975 \\
985\end{array}$ \\
\hline & 5 & $\begin{array}{l}31.80 \\
42.03\end{array}$ & $\begin{array}{l}41.5 \\
41.5\end{array}$ & $\begin{array}{l}.985 \\
.987\end{array}$ \\
\hline 6 & 6 & $\begin{array}{l}45.93 \\
50.93\end{array}$ & $\begin{array}{l}46.2 \\
50.9\end{array}$ & $\begin{array}{l}1.006 \\
0.999\end{array}$ \\
\hline 7 & 7 & $\begin{array}{l}56.19 \\
60.92\end{array}$ & $\begin{array}{l}55.9 \\
60.8\end{array}$ & $\begin{array}{r}.995 \\
.998\end{array}$ \\
\hline 8 & & 65.17 & 65.7 & 1.008 \\
\hline 9 & 8 & $\begin{array}{l}70.51 \\
75.78\end{array}$ & $\begin{array}{l}70.6 \\
76.3\end{array}$ & $\begin{array}{l}1.001 \\
1.007\end{array}$ \\
\hline & 9 & 81.50 & 81.2 & 0.996 \\
\hline 10 & 10 & $\begin{array}{l}86.12 \\
01.33\end{array}$ & $\begin{array}{l}85.8 \\
012\end{array}$ & $\begin{array}{l}.996 \\
000\end{array}$ \\
\hline 11 & & 96.74 & 96.6 & .999 \\
\hline
\end{tabular}

average deviation 0.006

and $\left(\mathrm{CH}_{3}\right)_{2} \mathrm{~S}_{3}$ are the same, and are $0.04 \mathrm{~A}$ shorter than the distance in $\left(\mathrm{CH}_{3}\right)_{2} \mathrm{~S} .{ }^{15}$ These shortenings are probably significant although they are within the limits of experimental error in each case. When sulfur forms single covalent bonds with two other atoms, the existing data indicate the angle decreases as the electronegativity of the bonded atoms increases: the observed values are $107^{\circ}$ in $\left(\mathrm{CH}_{3}\right)_{2} \mathrm{~S}_{2}, 105^{\circ}$ in $\mathrm{S}_{8}$, $104^{\circ}$ in $\left(\mathrm{CH}_{3}\right)_{2} \mathrm{~S}_{3}, 103^{\circ}$ in $\mathrm{S}_{2} \mathrm{Cl}_{2}$, and $101^{\circ}$ in $\mathrm{SCl}_{2}$.

In addition to the direct experimental evidence of the electron diffraction data, the sulfursulfur distance also suggests that the molecule has the straight chain structure $\mathrm{I}$, inasmuch as it is approximately equal to the $\mathrm{S}-\mathrm{S}$ distance in the singly bonded molecules just mentioned and is indeed just equal to the distance in $\left(\mathrm{CH}_{3}\right)_{2} \mathrm{~S}_{2}$, which is agreed to have the singly bonded structure; it is about $0.15 \mathrm{~A}$ greater than

${ }^{16}$ L. O. Brockway and H. O. Jenkins, J. Am.Chem. Soc. 58, 2036 (1936). would be expected for an $\mathrm{S}-\mathrm{S}$ bond of the type to be found in structure III and about $0.08 \mathrm{~A}$ greater than the average to be expected for structure II, on the basis of the Pauling-Huggins covalent radii. ${ }^{16}$ Although no test of these covalent-radius predictions of sulfur-sulfur multiple bonds is available, a rather close analogy can be drawn with the phosphorus-sulfur bonds in $\mathrm{P}_{4} \mathrm{~S}_{3}$, in which the bonds are presumed to be single bonds, as contrasted to the phosphorussulfur bonds in phosphorus sulfoxide, thiophosphoryl fluoride, and thiophosphoryl chloride. The $\mathrm{P}-\mathrm{S}$ distances in $\mathrm{P}_{4} \mathrm{O}_{6} \mathrm{~S}_{4}, \mathrm{PSF}_{3}$, and $\mathrm{PSCl}_{3}$ are $1.85 \mathrm{~A},{ }^{17} 1.85 \mathrm{~A},{ }^{18}$ and $1.94 \mathrm{~A},{ }^{19}$ respectively (the covalent radius sum for a double bond is $1.94 \mathrm{~A}),{ }^{16}$ while in $\mathrm{P}_{4} \mathrm{~S}_{3}$ the $\mathrm{P}-\mathrm{S}$ single bond distance is about $2.12 \mathrm{~A}^{20}$ (radius sum $2.14 \mathrm{~A}$ ). Here the $0.2 \mathrm{~A}$ difference between the lengths of the single and double bonds between phosphorus and sulfur is found to be valid, even though there might be some question, as there is for the special sulfursulfur bonds in structures II and III, as to whether the phosphorus-sulfur bond in the thiophosphoryl compounds should have the same length as that predicted in a conventional double bond.

The same conclusion is suggested by the bond angles of $104^{\circ}$. These bond angle values are reasonable for the singly bonded atoms in the chain structure I but they do not seem reasonable for the angles involving the doubly bonded sulfur atoms in structures II and III. For structure III, moreover, the $\mathrm{S}-\mathrm{S}-\mathrm{S}$ and $\mathrm{C}-\mathrm{S}-\mathrm{S}$ bond angles of $104^{\circ}$ correspond to a $\mathrm{C}-\mathrm{S}-\mathrm{C}$ bond angle of greater than $130^{\circ}$, an unreasonably high value by a wide margin.

${ }^{16}$ L. Pauling, The Nature of the Chemical Bond (Cornell University Press, I thaca, New York, 1940), second edition, Chapter IV.

17 A. J. Stosick, J. Am. Chem. Soc. 61, 1130 (1939).

18 D. P. Stevenson and H. Russell, J. Am. Chem. Soc. 61, 3264 (1939).

${ }_{19} \mathrm{~J}$. Y. Beach and D. P. Stevenson, J. Chem. Phys. 6, 75 (1938).

${ }^{20} \mathrm{O}$. Hassel and A. Petterson, Tids. Kjem. Bergvesen Met. 1, 57 (1941); Chem. Abs. 35, 4646 (1941). 